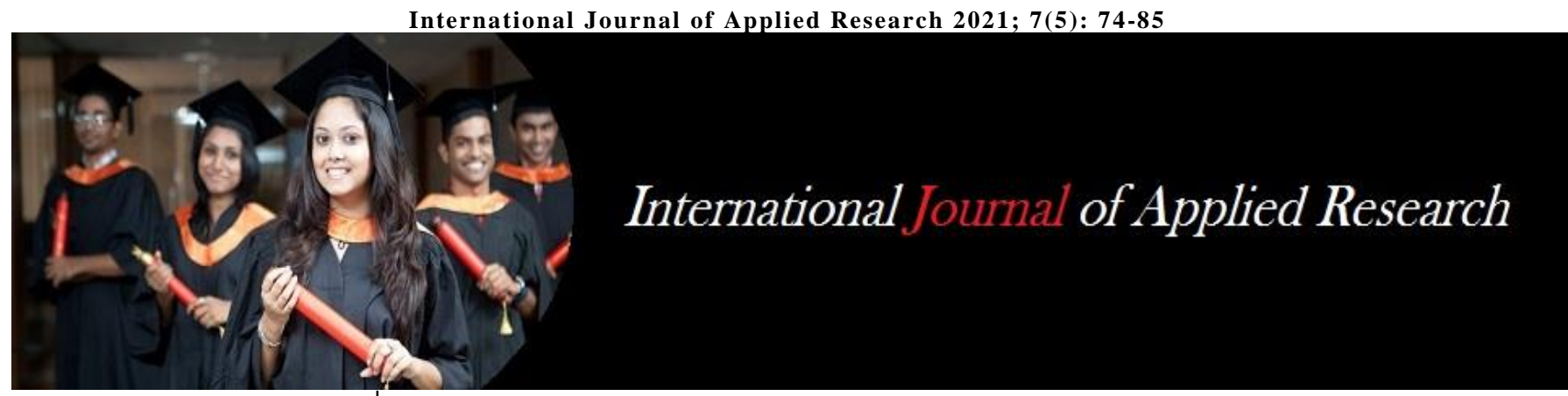

ISSN Print: 2394-7500 ISSN Online: 2394-5869 Impact Factor: 8.4

IJAR 2021; 7(5): 74-85 www.allresearchjournal.com

Received: 26-02-2021 Accepted: 11-04-2021

Dr. Nagesh Rajopadhye Astrology Researcher, Pune, Maharashtra, India

Abhishek Rajopadhye Computer Professional, Pune, Maharashtra, India

Madhura Rajopadhye Computer Professional, Pleasanton, California, USA

Parth Kulkarni

Astrology Researcher, Pleasanton, California, USA

Corresponding Author: Dr. Nagesh Rajopadhye astrobasedresearch@gmail.com Astrology Researcher, Pune, Maharashtra, India

\section{Empirical testing of few fundamental principles of Vedic astrology through comparative analysis of astrological charts of cancer diseased persons versus persons who never had it}

\author{
Nagesh Rajopadhye, Abhishek Rajopadhye, Madhura Rajopadhye and \\ Parth Kulkarni
}

DOI: https://doi.org/10.22271/allresearch.2021.v7.i5b.8548

\begin{abstract}
This article examines few fundamental principles of Vedic astrology through a systematic empirical experiment conducted on the birth charts of people who have suffered from cancer and people who have never had it in their life. Two data sets were formed, one consisting of 254 birth charts of people who were diagnosed with cancer before the age of 60 and the other one consisting 498 birth charts of people who had a long life of more than 80 years and never had cancer in their lifetime. In the absence of an authentic list of rules that predict cancer disease, we tested these two groups through a comprehensive statistical test where we compared astrological negativity as well as positivity (claimed to give unfavourable and favourable effects respectively) of all the planets, all houses and lords of all houses (entities). It was expected that if the principles involved are true, then both datasets would differ in their averages for one or more related parameters. It was however found that there was no statistically significant difference between the two data sets in terms of astrological negativity or positivity of any of the entities we tested. Two sample T-test of significance further confirmed these observations. We tested 23 fundamental principles of astrology for 34 entities and found none of them pass through the empirical test. Though we have not tested complete scope of astrology, these principles like a planet when conjugated with Saturn or Mars gives malefic effect or other principles regarding a house that has malefic planets or a lord of house in cruel nakshatra etc. are the basics of Vedic astrology and are something that one cannot do away with if astrology has to be practiced. Their invalidity proven through our test therefore raise a lot of questions about accuracy of predictions made by Vedic astrology using them.
\end{abstract}

Keywords: Vedic astrology, statistical testing, empirical test, cancer, long life

\section{Introduction}

In places such as India, astrology is an integral part of society. It may sound strange but the vast majority of arranged marriages are still happening only after matching birth charts. There are other elements involved in this decision such as religion, cast etc. but astrological compatibility is the very first filter applied invariably in the selection process. With many important life decisions being taken on the basis of astrology, India remains a major consumer of Vedic astrology. In addition, this reliance is not age-dependent and is in fact growing rapidly because of its popularity among the younger generation as well. This has occurred with the advent of mobile technology, accelerated via the Internet, and has reached new levels through social media. In an attempt to spread their cover in new areas, astrologers have begun to speak of medical astrology, a branch of astrology which claims to predict medical aspects of human lives (Anigol et al, 2020; Balaji, 2019; Chatterjee, (2007); Krishna, 2013; Krishna et al, 2019; Sharma et al, 2007) ${ }^{[2,3,6,13,14,27]}$. Given its tremendous impact on people and its ability to influence the society behaviour, it is necessary to test astrology thoroughly and scientifically. It is also necessary to examine astrologers' assertions about disease prediction because health is a sensitive topic and has a serious impact on human life.

When it comes to testing astrology, there have been numerous experiments carried out in the Western world (Carlson, 1985; Dean et. Al., 2000) ${ }^{[5,7]}$ but the debate remained inconclusive. For example, the former has subsequently been criticized for the misuse of the CPI as a 
dependent variable (Eysenck, 1986; Hamilton, 1986) [11, 12] and for inappropriate statistical analysis (Ertel, 2009) ${ }^{[10]}$. Dean has been a prominent critic of astrology and tested many claims of astrologers including sun signs and the outcome has been negative (Dean \& Mather, 2000; Dean \& Kelly, 2003; Dean et al., 2016) ${ }^{[7,8,9]}$. Though there has been extensive work in testing astrology in western world there are very few attempts reported in the context of Indian astrology (Bhandary, et al., 2018; Oshop \& Foss, 2005, Narlikar et al., 2009; Narlikar, 2013) ${ }^{[4,19,17,18]}$. Among these, the work done by Bhadary et al. and Oshop et al. is in support of astrology. In the work carried out by Bhandary et al. the test was not publicly conducted, the sample size has been smaller (of 75 in each group) and the exact astrological parameters used by astrologers for predictions are not detailed out. There is no scope for the researchers to repeat this experiment and verify. Contrary to the conclusions of Bhadary et al., Narlikar et al. showed that a success rate of astrologers participating in their double-blind test was marginally less than what would be achieved by tossing a coin. This test in our view is the first ever attempt to scientifically test Vedic astrology in India. It was a publicly held double-blind test of Indian astrology and created a lot of ripples in the society since it showed that astrologers failed to predict human attributes like intelligence. In such double-blind experiments however, particularly when the outcome is negative, an ambiguity remains whether the results are due to limitations of astrology or astrologers. A thorough testing of astrology on the basis of astrological principles, conducted at scale, through a scientifically designed empirical experiment is therefore a real need for time. With this background, an attempt is being made here to empirically test few of the most fundamental principles of Vedic astrology, with well defined criteria and by using a sufficiently large sample size of birth charts. While the full scope of astrology is not tested here, what we have tested here is the core of Vedic astrology, which consists of the most fundamental principles used in the everyday practice. These are regarded as the foundation of astrology in textbooks and in our opinion their importance is such that if they are proved or disproved, it is as good as validating or invalidating astrology.

\section{Methodology}

The approach to the design of this test was - form two distinct and opposite groups, analyse birth-chart the way astrology works by applying the principles or rules, measure astrological negativity and positivity associated with various entities and finally compare the average values of both groups through statistical methods to see if there is any significant difference. The methodology of empirical testing of this study consists of following steps

1. Define criteria for making two distinct and opposite groups of the data

2. Define astrological negativity and positivity, the parameters we want to measure

3. Define Measurement method

4. Develop experimental set up for the measurements

5. Define statistical techniques for comparison and analysis The details of each step are given in following sub-sections.

\subsection{Criteria definition}

One of the key factors for the success of empirical tests is to define the criteria on the basis of which two distinct groups are formed for comparison. Here, it is important that we do not leave room for interpretation and that the criteria be as objective as possible. We therefore selected a very clear criterion - whether the person was diagnosed with cancer before reaching the age of 60 . The criteria do not only refer to people with cancer, but state that the diagnosis must have taken place before the age of 60 . The reasons we chose to have this additional age-related criterion namely diagnosis before 60 are;

a. Based on the age distribution of 854 individuals with cancer, the data to which we had access to, a large proportion of the population (almost $70 \%$ ) was observed to get affected after the age of 60 . This creates some space for speculation that for those who are diagnosed of cancer post 60 , their cancer is part of aging effect and may therefore not reflect strongly in birth charts. By not taking the cases of those diagnosed post the age of 60 we have lost nothing but by excluding them we get advantage of leaving no room for such speculation.

b. In general, the impact of cancer on a person's life is very serious and disastrous when it occurs before the age of 60. Not only does it affect the lifespan of the diseased person, but it hampers his finances, career, mental health and the entire family. Very often, responsibilities remain unfulfilled and the patient's life is completely turned upside down. In most of these cases, the survival is not possible and the lifespan is shorter. Even if they survive, their lives are completely different because the shadow of death gets darker and hangs all through life. In addition, career, financial and relationship losses occurring during and post the illness make the remaining life miserable. If astrology is true, one expects such a severe impact on a person's life to show strong astrological signatures, especially with negative influence, in their birth charts which is expected to reflect in the test results.

Based on the above logic, we formed two groups of birth charts, Group A - people who were diagnosed with cancer before age of 60 and Group B - persons who lived longer than 80 years and never had cancer during their lifetimes. The reason we chose $80+$ age criteria for Group B is that we wanted to make it sufficiently evident that they completed their lifespan without having cancer and it did not interfere with their life in any way.

\subsection{Astrological negativity and positivity}

We have taken up this study with the objective of testing a few basic astrology principles which contribute to the negativity or positivity associated with the planet, the house or the lord of the house (hereafter all three together are referred as entities). These principles are fundamental in nature and are universally applied in astrology for everyday practice. It is a known fact that Astrology assumes that each planet or house in the birth chart has a significance towards a particular life effects (Raman, 1963; Raman, 1996, chapter 1, Rao, 2004, pp 79-84, Rao, 2004; Rath, 2012, pp23-170) [21, 22, 23, 24, 25]. For example, Mercury has significance for the native's intelligence, Venus and seventh house have significance for the marriage and so on. Since the purpose of this paper is to test the principles, we would like to elaborate a little more on them. One of the astrology principles states that when the planet is in debilitated zodiac sign the outcome of the life effect that is signified by the given planet is adverse (Agarwal, 2019, pp 125-130; Raman, 1996, chapter 1; Rao, $2004, \mathrm{pp} \mathrm{34})^{[1,22,23]}$. The counterpart of this principle affirms that if the planet is in the exalted zodiac sign, then the result related to significance of planet is beneficial. We call this as principle because it is universally applicable to all the planets. If we apply it to Mercury, a specific entity, it becomes a rule 
and will be used to predict intelligence. Similarly, if we apply the same principle to Venus, it will become a rule used to predict success in marriage. The principle is more generic in nature, considered as premise of astrology and is most agreeable, the reason why we focussed on them to test astrology. Another principle defined for the planets states that when the planet is conjugated with malefic planet like Saturn or Mars the outcome gets adversely affected (Agarwal, 2019, pp 125-130; Raman, 1996, chapter 3; Rao, 2004, pp 100-120) $[1,22,23]$. It's counterpart asserts on conjugation with auspicious planets like Jupiter or Moon and expect the outcome to be positive. Here the astrological configurations associated in these two examples, namely the planet in the debilitated or exalted sign in first example and the planet in the conjugation with malefic or auspicious planets in second example, are considered to create astrological negativity or positivity respectively which in turn are seen as giving rise to adverse or good effects in the life. Likewise, there are several principles in astrology which are applied to all entities, which presumably signify various aspects of our life and accordingly the predictions, either good or bad, are made. Testing these principles is therefore as good as testing a major aspect of astrology because astrology cannot be practiced without applying them. Having seen what we mean by principles and how they reflect in birth chart in terms of astrological negativity and positivity, we now come to the principles that we have actually tested in this exercise.

Since we have two exactly opposite groups in terms of characteristics, namely suffering by cancer disease, comparing them for compliance to the rule that predicts cancer is the most ideal way of conducting this empirical testing. It must be noted, however, that in astrology there is no single rule that one can check and predict. In fact, there are always a large number of rules set out to predict a good or bad outcome of a particular life effect. This is because astrology assumes that for any life effect there are planet(s), house(s) and lord(s) of house(s) that are significant and they all need to be taken into account. A prediction of an adverse effect of life will therefore be made on the basis of the total negativity associated with entities which are considered as significant. The negativity in these significant entities comes through complying with various negative rules. The way astrology is practiced, the approach to define the rules for cancer would go through following steps;

Step 1: Identify entities (planets, houses and lords of houses) that are significant for the cancer.

Step 2: Shortlist the principles that predict adverse effects and apply them to the identified entities.

For instance, for predicting cancer some astrologers may evaluate Saturn and Rahu as planets of significance, $1^{\text {st }}$ and 6 th house as houses of significance and the lords of $1^{\text {st }}$ and $6^{\text {th }}$ house as significant lords of houses. (Agarwal, 2019, pp 125130; Chatterjee, 2007) ${ }^{[1,6]}$. For predicting adverse effect like cancer, the negativity involved in these entities is evaluated by means of applying negative principles and measuring how many of them are complied with. Here there is no authentic guideline in terms of minimum number of rules that should be complied with for predicting the disease and therefore the judgement of that number will differ from astrologer to astrologer. From our testing point of view however, if those principles are true, the compliance will always be more in Group A (Cancer diseased) than Group B. The only challenge in defining such cancer specific rules is that there are too many different opinions on which entities are exactly significant for predicting the cancer. The use of cancerspecific rules in empirical tests would therefore be questionable and will not be a fruitful exercise.

On this background, a new approach for comprehensive testing has been developed for this study. In this approach, we have shortlisted two sets of fundamental principles of astrology, one that predict adverse effects, and another one that predicts good or benefic (beneficial) effects. For the purposes of the present article, we call them 'negative principles' and 'positive principles' respectively. Given the diversity of opinions regarding planets or houses that are significant for predicting cancer, we applied these principles to all entities, that is, to all individual planets, all twelve houses and also lords of these twelve houses. Please note that when the negative principle is applied to an entity, it becomes a 'negative rule'. And when the positive principle is applied it becomes 'positive rule'. We measured negativity and positivity associated with each entity based on the compliance to negative and positive rules respectively. Details about their calculations are provided in the following section. The comparison of astrological negativity and positivity in two groups of birth charts was carried out for each entity using statistical techniques. The rationale behind this test approach is that regardless of which entity is significant for cancer if the negative or positive principles we are testing are true they will result in significant difference in compliance between two groups for atleast one entity. With this approach we cover different opinions about the significance of the planets and houses for prediction of cancer and hence we call this a novel approach.

The most important aspect of this study was to identify the right negative and positive principles to use in the test. Since there is no single authentic document depicting these principles, we went through a number of books and research articles (Agarwal, 2019, pp 125-130; Krishna, 2013 Raman, 1996; Rao, 2004, pp 100-140; Rath, 2012; Rath, 2018, pp 205-208) [1, 13, 22, 23, 25, 26], deliberated with number of astrologers and prepared our list. The idea was to have principles that are universally agreeable and hence we selected only those which are given as fundamental principles in the astrology textbooks. Our list of negative and positive principles shortlisted for the planet, house and the lord of house is given through Table 1 to Table 4 . We believe that there will be no disagreement with them from astrological point of view although there can still be differences of opinion about which entities they should be applied to, the part that is well covered by our comprehensive testing approach.

\subsection{Measuring astrological negativity and positivity}

In order to measure astrological negativity and positivity in terms of numbers, we have to quantify everything which has significance from an astrological point of view. It is necessary to add here that there is no standard method of quantification of astrological negativity or positivity. So, our method and the numbers should be looked at as an abstract, and good for comparison purposes only. Unfortunately, the computation process becomes a little complex to execute, but that's because astrological analysis itself is a very complicated process and involves too many complex phenomena. The 
details of how we translated the negativity and positivity of entities into numbers are provided below.

\subsubsection{Characterisation of each planet}

The very first step before we turn to rules for measuring compliance is to characterise the planets themselves. One of the assumptions of Astrology is that a planet has a favourable or adverse effect according to its dignity or the sign to which it belongs to (Raman, 1996, chapter 1; Rao, 2004, chapter 3) $[22,23]$. In addition, for adverse effects it also matters whether or not the planet is in retrograde. These two effects are inherent to the planet means they are not arising out of any external configuration but are part of the original property of the planet for the given birth chart. We therefore defined two variables for each planet, one that multiplies the ability of a planet to have an auspicious or benefic effect called here as 'strength multiplicand', denoted as $\alpha$ (planet) and another which multiplies malefic effects called here as 'malefic multiplicand', termed here as $\beta$ (planet). Following the same hierarchy followed by astrology in terms of ability to add into benefic or malefic effect depending on the zodiac sign it belongs to (Raman, 1996, chapter 1; Rao, 2004, chapter 3) ${ }^{[22,}$ ${ }^{23]}$, we have assigned the values of these multipliers as shown in Table 5 and Table 6 . We must add here that rational behind assigning these values is to create a scale for intensity of the effect of planet. Since these multiplicands are getting applied in both groups in same manner and we are only using them for comparison purpose their exact values given in Table 5 and 6 do not matter as long as we maintain the hierarchy. It should also be noted that in astrology every planet can have a benefic (auspicious) as well as a malefic effect and hence both, positivity and negativity, are calculated separately without summing them together as a single value.

\subsubsection{Measuring the rule compliance}

In astrology, applying a rule means checking for a specific configuration in a birth chart.

We considered compliance to the negative rules as a measure of astrological negativity and compliance to positive rules as measure of positivity for the entity under test. We measured following numbers for each entity as the representative of negativity and positivity and they become the primary inputs to our statistical tests:

$\mathrm{NRa}=$ Number of negative rules applied

$\mathrm{NRc}=$ Number of Negative rules complied

$\mathrm{PRa}=$ Number of Positive rules applied

$\mathrm{PRc}=$ Number of Positive rules complied

As such, the above should have been sufficient for the purpose of comparison, but astrology also emphasizes the examination of the intensity with which the rule is observed. For example, if a rule for cancer involves conjugation of Rahu and Saturn, the rule may get complied if they are in conjugation but the same conjugation is said to increase the intensity of the negative effect and probability of occurrence of cancer if one or both of these planets are debilitated. To take into account these considerations, we now introduce a concept of 'compliance score' for each rule using $\alpha$ and $\beta$ values of planets defined in 2.3.1 above. If the rule is not complied, the compliance score is zero. If the rule is adhered to, the compliance score formula for the negative rule is;
Compliance score of a Negative Rule for the entity

$(\mathrm{CSN})=[(-20) \times \Pi \beta($ planet $\mathrm{n})]$

i

Where (-20) is a constant used just to create the comparison scale, $\mathrm{n}$ is number of planets involved in the rule and $\beta$ (planet) plays the multiplier role as explained above. For example, If the rule 1.1 is applied on Rahu for conjugation with Saturn or Mars or Uranus and if all three are in conjugation with Rahu (a hypothetical case only), then $n=4$ and

$(\mathrm{CSN}$ for rule 1.1 of Rahu $)=(-20) \times(\beta($ Rahu $) \times \beta($ Saturn $) \times$ $\beta$ (Mars) x $\beta$ (Uranus))

As another example, if the CSN is calculated for say $6^{\text {th }}$ house for rule 2.1 which checks presence of malefic planets in the house then $n$ will be number of malefic planets present in the house. The compliance score will thus represent the magnitude of negativity involved while complying the rule. Likewise, the values of the CSN are calculated for each planet using all the negative rules of Table 1 , for each house using all the rules of Table 2 and for each lord of house using all the rules of Table 1 and the summations becomes,

$$
\begin{aligned}
& \sum \mathrm{CSN} \text { for the entity is }=\underset{\mathrm{i}=1}{\mathrm{CSN}(\mathrm{i})} \text { where } \mathrm{n} \text { is no of rules } \\
& \text { complied by given entity. }
\end{aligned}
$$

The measurement logic for measuring compliance score of the positive rule also remains the same as that of negative rule except that it is a positive value and we make use of $\alpha$ (planet) value in calculations.

Compliance score of a Positive Rule for the entity

$$
\begin{gathered}
\text { n } \\
(\mathrm{CSP})=[(+20) \times \Pi \beta \text { (planet } \mathrm{n})] \\
\mathrm{i} \\
\sum \mathrm{CSP} \text { for the entity is }=\underset{\mathrm{i}=1}{\sum \mathrm{CSP}(\mathrm{i})}
\end{gathered}
$$

where $\mathrm{n}$ is the no of rules complied.

Thus, NRc and the summation of compliance scores that is $\sum \mathrm{CSN}$ represent astrological negativity of an entity whereas PRc and $\sum$ CSP represent astrological positivity of entity. Their values were calculated for all entities and were passed on to the statistical test for comparison.

\subsection{The experimental setup}

A computer-based solution was developed to perform the testing as per details given above. There are three components to the solution.

\subsubsection{Software for casting the birth chart}

It reads birth details from an excel sheet, makes use of commercially available APIs to cast birth charts and write details like planetary positions, dignities, retrogrades, house number etc. in the database using Lahiri ayanamsa system (Rao, 2004, p18) ${ }^{[23]}$. 


\subsubsection{Analyser Engine}

This component applies various rules, measures which ones comply and calculates the compliance scores. A database consisting of $\mathrm{NRa}, \mathrm{NRc}, \sum \mathrm{CSN}, \mathrm{NPa}, \mathrm{PRc}$ and $\sum \mathrm{CSP}$ is created for each astrological entity. Python based automation developed in this module enables the software to cast and process hundreds of birth charts of Group A and Group B in one go.

\subsection{Statistical testing}

Two sample T- test of unequal variances was run on averages of NRc, PRc values as well as averages of $\sum$ CSN and $\sum$ CSP values of Group A and B for all entities involved in the test. Here the Null Hypothesis is that the difference in the averages of the parameter under test between the two groups is equal to or less than 10 percentage. To be precise, this hypothesis is basically saying that there is no difference in the compliance of rules or the scores in the two groups beyond $10 \%$ and hence astrological principles under test are not valid. The alternative Hypothesis is that the difference between two groups is over $10 \%$, thus confirming the validity of those principles. As such, if astrological principles we tested are true and if they have to give prediction on life critical matters, the difference between two groups is expected to be much more, of the order of $50 \%$ at least, as against $10 \%$ we are testing here and hence it is a very liberal and easy test for astrological principles to pass through. At the same time, testing a null hypothesis with $10 \%$ hypothetical difference criteria is the most stringent test for us to refute those principles. However, we decided to run the test this way to avoid any ambiguity and to give maximum benefit to astrological principles to get proved.

\section{Data}

One of the characteristics of Vedic astrology is that it critically makes use of time of birth or the planetary position of the Moon and generally this information is not easily available in the public domain. Even though this information is collected at the individual level, the accuracy of the data and the bias are always questioned, especially when the results are not to be accepted. It is for this reason that we chose to take data from Astrodatabank (Lois Rodden's Astro Databank, 2008) ${ }^{[15,16]}$ where accuracy ratings are maintained systematically and data is collected worldwide without any bias.

For obtaining birth details of people belonging to Group A, this database was filtered using following three selections in the same order as they are given below;

- For the entries of Rodden rating AA (considered as most accurate entries)

- Date of birth after 1900.

- Category: This went through the first selection as Diagnoses, second as Major Diseases and third one as Cancer

We had about 853 entries of cancer diagnosed people with these selections. We then went through the details of each entry in order to select people diagnosed with cancer before the age of 60. As a result of this selection, 254 entries were taken forward as Group A.

For Group B too we used Rodden rating AA and Date of births after 1900 as first two filters. We then used a selection of 'long life more than 80 years' under 'death' category and further filtered data for cases who were never diagnosed with cancer. We got 498 cases from this selection for Group B who are individuals who lived longer than 80 , have died for a variety of reasons but not due to cancer and have never had cancer in their lifetime.

Statistical test calculator (Public service of Creative Research Systems) ${ }^{[20]}$ used in this experiment stipulated that we need to have a minimum sample size of 661 (both groups together) to achieve a confidence level of $99 \%$ and a confidence interval of $5 \%$ to test the difference in the two groups. Our data size of 254 cases of Group A and 498 cases of Group B meet this criterion. The results presented here are in terms of averages or percentages and hence different size of data of two groups does not matter.

\section{Statistical Analysis}

Results obtained for of NRc, PRc, $\sum$ CSN and $\sum$ CSP for all entities and corresponding $\mathrm{T}$ test values are given in Table 7. It is clearly seen that none of the entities have any significant difference (greater than 10 percent) in terms of compliance when compared within the two groups. This applies to both negative and positive rules. If principles we tested are true, we should have seen more negativity in the average compliance scores or average number of negative rules complied (NRc) in Group A, but this was not seen. There have been reports that Saturn and Rahu are responsible for

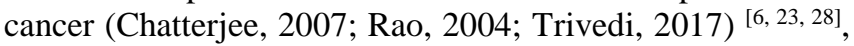
however we can see that their negativity is of the same order in both groups and it cannot act as a differentiator for prediction. If we consolidate all the other rules for cancer diseases (Krishna et al.,2019; Sharma, 2017; Trivedi, 2017) $[14,27,28]$, we have at least five major planets considered significant for cancer: Saturn, Rahu, Mars, Jupiter and the Sun. Not just these planets, but our results show that none of the ten planets have any significant negativity in Group A that can be used for prediction. At the same time, none of them have significantly higher positivity in Group B, indicating that the two groups do not differ in any way.

To take our investigation to the next level we also compared compliance of each of the negative and positive principles given in Table 1 for Rahu which is traditionally considered to be significant for cancer disease. From T-test probability values given in Table-8, it was observed that Null Hypothesis could not be rejected for any of the rules. This means each rule complies equally in both the groups. From an astronomical point of view, the astrological configurations involved in the rule are nothing but a certain placement of planets in the sky. The rules state that the probability of having such planetary positions is greater when people in group A took birth. However, the empirical test results in Table 8 refuted those rules for Rahu by observing that the probabilities are equal in both groups. These rules were also tested for Mars and Sun which some astrologers believe are significant for the disease but the results were no different. Results are not given here to avoid repetition and for space reasons but it clearly shows that the underlying principles of these rules are not valid. Testing the individual principle for every planet is a little tricky and needs to be done with great care. According to the pace of the planet and the configuration involved, the number of cases that comply the rule will vary considerably from one rule to another. We must therefore ensure that post compliance there are sufficient number of cases to verify the hypothesis from a statistical 
perspective. For this reason, we shall return to this analysis in detail for all other planets especially the slower ones namely Jupiter and Saturn in subsequent studies. Nevertheless, the observations we have made concerning Rahu, the Sun and Mars are very important because, first and foremost, they prove that these rules themselves are invalid though they are based on the most fundamental principles of astrology. Secondly, they prove that the combination of these planets and the principles we tested cannot be used for predictions as is done currently.

In our test we also applied rules to the Ascendant using its degrees and zodiac sign. As Ascendant is not a planet, it does not have debilitated or exalted signs associated with it and hence some of the rules of Table 1 and Table 3 are not applicable. For the applicable rules however, it has shown no significant difference in compliance. The Ascendant is a fundamental and an important phenomenon in astrology and various astrological configurations, either of auspicious or malefic in nature, are regarded as having major effects on natives (Agarwal, 2019, pp 125-130; Raman, 1996; Rao, 2014; Rath, 2012, Rath, 2018) ${ }^{[1,22,23,25,26]}$. As can be seen from the results we did not find this theory to be true in our testing.

What has become evident by the testing of the planets is also true for houses and lords of houses as seen from Table 7. Since none of them differ in their negativity or positivity despite their natives being exactly opposite, we prove that regardless of which house or lord is considered as 'significant for cancer' by astrology, they actually cannot act as a basis for prediction, if the principles that we tested are to be used. We can look more closely at the sixth house which is supposed to be important for health (Anigol, 2020; Chatterjee, 2007; Raman 1996; Rao, 2004) [2, 6, 22, 23] and should have got impacted in group A. However, neither $6^{\text {th }}$ house, nor its lord has any difference in negativity when compared to group B showing that the assumption is not empirically proven as long as the principles we tested are used to assess its negativity. Eighth house, which is traditionally linked to disease, longevity, death etc (Agarwal, 2019; Chatterjee, 2007; Raman 1996; Rao, 2004) [1, 6, 22, 23] also did not show any difference, either in terms of negativity or positivity proving again that these assumptions are invalid. The groups we have formed have distinct differences in terms of life longevity specifically and this should have shown up through the $8^{\text {th }}$ house or its lord planet or through any other entity for that matter, but that did not happen.

If we consolidate, we tested all 9 negative principles individually for couple of planets which directly showed their invalidity. Moreover, as part of comprehensive testing, in total we tested 34 entities and 68 parameters (considering negativity and positivity for each entity) but none of them differ beyond $10 \%$ in both groups, which shows the actual state of astrology. Despite this extensive testing, there will always be arguments about what has not been done and about additional rules that should have been tested. We certainly do not claim that we have tested complete scope of astrology. However, we do not want to lose sight of what is already established here with complete clarity. There is a need for astrology users to verify validity of the principles of astrology on their part too, using statistical techniques, before making predictions. While more principles can always be tested, there should be a logical explanation as to why none of the 68 parameters of our comprehensive test could show any difference whereas they were supposed to be substantially different from the astrological perspective. Our results show that prima facie there is nothing like 'unique configuration' in birth-charts especially when a large number of birth-charts are observed. Astrology researcher and user community must verify the configuration(s) empirically by forming two groups and ensuring the data size stipulated in section 3.0 before using them for predictions. The data for such research must also come from an unbiased source. Such attempts are however not seen anywhere in the published material. This is required because the principles we proved as invalid in this experiment are also invariably used to predict other life effects in everyday practice by applying to various entities. For instance, the rules listed in Table 1 and Table 2 are also used to predict unfavourable marriage outcomes by applying to Venus and $7^{\text {th }}$ house respectively. And this goes on for almost all areas of predictions done by astrology. Such predictions or interpretations influence how society conducts itself with the natives which is unfair and unjustified, particularly when the underlying principles are not empirically proven. Considering the role that Vedic astrology plays today to influence social psychology, particularly in India, this calls for an extensive and in-depth investigation.

Table 1: List of negative principles tested for each planet. The same set of principles was also used for testing planets which act as 'lord of house'

\begin{tabular}{|c|l|}
\hline Sr. No. & \multicolumn{1}{c|}{ Principles } \\
\hline 1.1 & Planet is in conjugation or square or opposite to Saturn, Mars, Rahu, Ketu or Uranus \\
\hline 1.2 & Planet is in debilitated state in D9 chart \\
\hline 1.3 & Planet is in $6^{\text {th }}, 8^{\text {th }}$ or $12^{\text {th }}$ house \\
\hline 1.4 & Planet is in malefic nakshatra namely Krittika, Ashelsha, Mul \\
\hline 1.5 & Planet is Retrograde \\
\hline 1.6 & $\begin{array}{l}\text { Planet is afflicted by } 3^{\text {rd }} \text { or } 10^{\text {th }} \text { aspect of Saturn or } 4^{\text {th }} \text { or } 8^{\text {th }} \text { aspect of Mars (If afflicted by both planets simultaneously } \\
\text { compliance scores get added accordingly) }\end{array}$ \\
\hline 1.7 & Lord of planet's house is placed in debilitated or in enemy sign \\
\hline 1.8 & Planet itself is in debilitated or in enemy sign \\
\hline 1.9 & Planet is in conjugation with lord of $6^{\text {th }}$ or $8^{\text {th }}$ or $12^{\text {th }}$ house \\
\hline $\begin{array}{l}\text { Note: If multiple planets are involved while complying the rule, the } \beta \text { values of all planets complying with the rule contribute to the } \\
\text { formula of compliance score }\end{array}$ \\
\hline
\end{tabular}


Table 2: List of negative principles tested for each house of birth chart

\begin{tabular}{|c|c|}
\hline Sr. No. & Principles \\
\hline 2.1 & Malefic planets like Saturn, Mars, Rahu or Ketu or Uranus are placed in house \\
\hline 2.2 & Lord of $6^{\text {th }}$ or $8^{\text {th }}$ or $12^{\text {th }}$ house is placed in the house \\
\hline 2.3 & Saturn or Mars placed just opposite to the house \\
\hline 2.4 & House afflicted by $3^{\text {rd }}$ or $10^{\text {th }}$ aspect of Saturn or by $4^{\text {th }}$ or $8^{\text {th }}$ aspect of Mars \\
\hline
\end{tabular}

Table 3: List of positive principles tested for each planet. The same set of principles was also used for testing planets which act as 'lord of house'

\begin{tabular}{|c|l|}
\hline Sr. No & \multicolumn{1}{c|}{ Principles } \\
\hline 3.1 & $\begin{array}{l}\text { Planet is in conjugation or opposite or sextile or trine with Venus or Jupiter (If rule is complied with both planets } \\
\text { simultaneously the compliance scores are added accordingly) }\end{array}$ \\
\hline 3.2 & Planet is influenced by $5^{\text {th }}$ or $9^{\text {th }}$ aspect of Jupiter \\
\hline 3.3 & Planet is in Exalted or friendly sign in D9 chart \\
\hline 3.4 & Planet is placed in $1^{\text {st }}, 4^{\text {th }}, 5^{\text {th }}, 9^{\text {th }}$ or $11^{\text {th }}$ house \\
\hline 3.5 & Planet itself is in exalted or own sign \\
\hline 3.6 & Lord of planet's house is in exalted state or is in it's own sign \\
\hline & $\begin{array}{l}\text { Note: If multiple planets are involved while complying the rule, the } \alpha \text { values of all planets complying with the rule contribute } \\
\text { to the formula of compliance score }\end{array}$ \\
\hline
\end{tabular}

Table 4: List of positive principles tested for each house of birth chart

\begin{tabular}{|c|l|}
\hline Sr. No. & \multicolumn{1}{|c|}{ Principles } \\
\hline 4.1 & Venus, Jupiter or Moon placed in the house \\
\hline 4.2 & Venus, Jupiter or Moon placed in opposite house \\
\hline 4.3 & House is influenced by $5^{\text {th }}$ or $9^{\text {th }}$ aspect of Jupiter \\
\hline 4.4 & Lord of $1^{\text {st }}, 4^{\text {th }}, 5^{\text {th }}, 9^{\text {th }}$ or $11^{\text {th }}$ houses placed inside the house \\
\hline
\end{tabular}

Note: If multiple planets are involved while complying the rule, the $\alpha$ values of all planets complying with the rule contribute to the formula of compliance score

Table 5: Values of $\alpha$ (planet)

\begin{tabular}{|c|c|c|c|c|c|}
\hline & $\begin{array}{c}\text { Planet in Exalted zodiac } \\
\text { sign within } \pm \mathbf{4} \text { degrees of } \\
\text { exact exaltation }\end{array}$ & $\begin{array}{c}\text { Planet in exalted zodiac sign but } \\
\text { not within } \mathbf{\pm} \text { degrees of exact } \\
\text { exaltation }\end{array}$ & $\begin{array}{c}\text { Planet in it's } \\
\text { own zodiac } \\
\text { sign }\end{array}$ & $\begin{array}{c}\text { Planet in } \\
\text { friendly zodiac } \\
\text { sign }\end{array}$ & $\begin{array}{c}\text { Planet in other } \\
\text { zodiac signs }\end{array}$ \\
\hline $\begin{array}{c}\alpha \\
\text { (planet) }\end{array}$ & 2 & 1.5 & 1.25 & 1.1 & 1 \\
\hline
\end{tabular}

Table 6: Values of $\beta$ (planet)

\begin{tabular}{|c|c|c|c|c|}
\hline & $\begin{array}{c}\text { Planet in debilitated sign } \\
\text { within } \mathbf{\pm} \text { degrees of exact } \\
\text { debilitation }\end{array}$ & $\begin{array}{c}\text { Planet in debilitated zodiac sign but } \\
\text { not within } \mathbf{4} \text { degrees of exact } \\
\text { debilitation }\end{array}$ & $\begin{array}{c}\text { Planet in } \\
\text { enemy zodiac } \\
\text { sign }\end{array}$ & $\begin{array}{c}\text { Planet in } \\
\text { other zodiac } \\
\text { signs }\end{array}$ \\
\hline $\begin{array}{c}\beta \text { (planet) values if } \\
\text { planet is not } \\
\text { Retrograde }\end{array}$ & 2 & 1.5 & 1.25 \\
\hline $\begin{array}{c}\beta \text { (planet) values if } \\
\text { planet is Retrograde }\end{array}$ & 2.5 & 2 & 1.75 & 1.5 \\
\hline
\end{tabular}

Table 7: Comparison of averages of NRc, PRc, $\Sigma$ CSN and $\sum$ CSP and T test results

\begin{tabular}{|c|c|c|c|c|c|c|}
\hline \multicolumn{2}{|c|}{$\begin{array}{c}\text { Group A } \\
\text { (Birth-charts of Cancer persons) }\end{array}$} & \multirow[b]{2}{*}{$\begin{array}{l}\text { Rules/Applied } \\
\text { entity }\end{array}$} & \multicolumn{2}{|c|}{$\begin{array}{c}\text { Group B } \\
\text { (Birth-charts of people who have } \\
\text { Longlife with no cancer) }\end{array}$} & \multicolumn{2}{|c|}{ T Test results } \\
\hline $\begin{array}{c}\text { Average of } \\
\left(\sum C S N\right) \text { for } \\
\text { negative rules } \\
\text { and }\left(\sum C S P\right) \\
\text { for positive } \\
\text { rules }\end{array}$ & $\begin{array}{c}\% \text { of Average } \\
\text { number of rules } \\
\text { complied (NRc } \\
\text { for negative rules } \\
\text { and PRc for } \\
\text { positive rules) }\end{array}$ & & $\begin{array}{c}\text { Average of } \\
\left(\sum C S N\right) \text { for } \\
\text { negative rules } \\
\text { and }\left(\sum C S P\right) \\
\text { for positive } \\
\text { rules }\end{array}$ & $\begin{array}{l}\% \text { of Average } \\
\text { number of rules } \\
\text { complied (NRc } \\
\text { for negative rules } \\
\text { and PRc for } \\
\text { positive rules) }\end{array}$ & $\begin{array}{c}\text { P value for } \\
\text { Compliance } \\
\text { scores (for } \sum \text { CSN } \\
\text { and } \sum \text { CSP as } \\
\text { applicable) }\end{array}$ & $\begin{array}{l}\text { P value for No } \\
\text { of rules } \\
\text { complied (for } \\
\text { NRc and PRc as } \\
\text { applicable) }\end{array}$ \\
\hline-38.3 & $12.95 \%$ & $\begin{array}{l}\text { Negative rules } \\
\text { applied to } \\
\text { ASCENDANT }\end{array}$ & -33.1 & $12.96 \%$ & 0.06 & 0.99 \\
\hline 50.5 & $32.81 \%$ & $\begin{array}{l}\text { Positive rules } \\
\text { applied to } \\
\text { ASCENDANT }\end{array}$ & 51.6 & $33.40 \%$ & 0.53 & 0.55 \\
\hline-50.1 & $21.04 \%$ & $\begin{array}{l}\text { Negative rules } \\
\text { applied to SUN }\end{array}$ & -47.3 & $20.04 \%$ & 0.33 & 0.32 \\
\hline
\end{tabular}




\begin{tabular}{|c|c|c|c|c|c|c|}
\hline 41.1 & $35.96 \%$ & $\begin{array}{l}\text { Positive rules } \\
\text { applied to SUN }\end{array}$ & 44.7 & $37.15 \%$ & 0.13 & 0.40 \\
\hline-50.2 & $21.74 \%$ & $\begin{array}{c}\text { Negative rules } \\
\text { applied to MOON }\end{array}$ & -48.1 & $21.84 \%$ & 0.49 & 0.92 \\
\hline 38.6 & $33.79 \%$ & $\begin{array}{c}\text { Positive rules } \\
\text { applied to MOON }\end{array}$ & 39.3 & $33.90 \%$ & 0.76 & 0.94 \\
\hline-45.8 & $19.55 \%$ & $\begin{array}{c}\text { Negative rules } \\
\text { applied to MARS }\end{array}$ & -45.6 & $19.92 \%$ & 0.95 & 0.72 \\
\hline 45.6 & $35.30 \%$ & $\begin{array}{c}\text { Positive rules } \\
\text { applied to MARS }\end{array}$ & 43.7 & $35.34 \%$ & 0.43 & 0.98 \\
\hline-56.6 & $24.28 \%$ & $\begin{array}{l}\text { Negative rules } \\
\text { applied to } \\
\text { MERCURY } \\
\end{array}$ & -53.6 & $23.38 \%$ & 0.33 & 0.43 \\
\hline 45.7 & $35.70 \%$ & $\begin{array}{l}\text { Positive rules } \\
\text { applied to } \\
\text { MERCURY }\end{array}$ & 46.5 & $37.15 \%$ & 0.74 & 0.29 \\
\hline-57.3 & $24.15 \%$ & $\begin{array}{l}\text { Negative rules } \\
\text { applied to } \\
\text { JUPITER } \\
\end{array}$ & -57.5 & $24.34 \%$ & 0.97 & 0.87 \\
\hline 36.0 & $30.77 \%$ & $\begin{array}{c}\text { Positive rules } \\
\text { applied to } \\
\text { JUPITER }\end{array}$ & 36.1 & $30.86 \%$ & 0.96 & 0.95 \\
\hline-54.0 & $21.74 \%$ & $\begin{array}{c}\text { Negative rules } \\
\text { applied to VENUS }\end{array}$ & -51.4 & $20.39 \%$ & 0.43 & 0.19 \\
\hline 37.7 & $33.60 \%$ & $\begin{array}{c}\text { Positive rules } \\
\text { applied to VENUS }\end{array}$ & 38.8 & $34.61 \%$ & 0.64 & 0.46 \\
\hline-58.1 & $24.98 \%$ & $\begin{array}{c}\text { Negative rules } \\
\text { applied to } \\
\text { SATURN }\end{array}$ & -48.5 & $21.17 \%$ & $0.07^{\#}$ & $0.20^{\#}$ \\
\hline 46.7 & $33.92 \%$ & $\begin{array}{c}\text { Positive rules } \\
\text { applied to } \\
\text { SATURN }\end{array}$ & 49.0 & $34.24 \%$ & 0.35 & 0.83 \\
\hline-39.1 & $19.03 \%$ & $\begin{array}{c}\text { Negative rules } \\
\text { applied to RAHU }\end{array}$ & -38.0 & $18.34 \%$ & 0.67 & 0.52 \\
\hline 43.5 & $34.19 \%$ & $\begin{array}{c}\text { Positive rules } \\
\text { applied to RAHU }\end{array}$ & 48.3 & $36.91 \%$ & $0.49^{\#}$ & 0.05 \\
\hline-33.2 & $15.27 \%$ & $\begin{array}{l}\text { Negative rules } \\
\text { applied to KETU }\end{array}$ & -36.6 & $16.51 \%$ & 0.15 & 0.19 \\
\hline 41.3 & $29.66 \%$ & $\begin{array}{c}\text { Positive rules } \\
\text { applied to KETU }\end{array}$ & 45.1 & $28.41 \%$ & 0.09 & 0.30 \\
\hline-32.3 & $31.99 \%$ & $\begin{array}{l}\text { Negative rules } \\
\text { applied to } \\
\text { HOUSE1 } \\
\end{array}$ & -29.6 & $29.67 \%$ & 0.22 & 0.26 \\
\hline 23.4 & $24.51 \%$ & $\begin{array}{l}\text { Positive rules } \\
\text { applied to } \\
\text { HOUSE1 }\end{array}$ & 22.9 & $23.19 \%$ & 0.80 & 0.43 \\
\hline-27.7 & $27.17 \%$ & $\begin{array}{c}\text { Negative rules } \\
\text { applied to } \\
\text { HOUSE2 } \\
\end{array}$ & -30.7 & $30.02 \%$ & 0.16 & 0.15 \\
\hline 20.4 & $21.56 \%$ & $\begin{array}{l}\text { Positive rules } \\
\text { applied to } \\
\text { HOUSE2 } \\
\end{array}$ & 23.5 & $23.44 \%$ & 0.07 & 0.25 \\
\hline-30.7 & $30.51 \%$ & $\begin{array}{c}\text { Negative rules } \\
\text { applied to } \\
\text { HOUSE3 } \\
\end{array}$ & -30.0 & $29.72 \%$ & 0.73 & 0.70 \\
\hline 21.9 & $22.64 \%$ & $\begin{array}{l}\text { Positive rules } \\
\text { applied to } \\
\text { HOUSE3 }\end{array}$ & 20.2 & $20.63 \%$ & 0.32 & 0.23 \\
\hline-27.8 & $27.07 \%$ & $\begin{array}{c}\text { Negative rules } \\
\text { applied to } \\
\text { HOUSE4 } \\
\end{array}$ & -29.0 & $29.87 \%$ & 0.57 & 0.16 \\
\hline 19.7 & $19.98 \%$ & $\begin{array}{l}\text { Positive rules } \\
\text { applied to } \\
\text { HOUSE4 }\end{array}$ & 20.8 & $22.34 \%$ & 0.54 & 0.15 \\
\hline-31.1 & $30.71 \%$ & $\begin{array}{c}\text { Negative rules } \\
\text { applied to } \\
\text { HOUSE5 } \\
\end{array}$ & -30.7 & $30.32 \%$ & 0.84 & 0.85 \\
\hline 22.6 & $22.74 \%$ & $\begin{array}{l}\text { Positive rules } \\
\text { applied to } \\
\text { HOUSE5 }\end{array}$ & 20.8 & $21.74 \%$ & 0.29 & 0.54 \\
\hline
\end{tabular}




\begin{tabular}{|c|c|c|c|c|c|c|}
\hline-31.9 & $31.30 \%$ & $\begin{array}{l}\text { Negative rules } \\
\text { applied to } \\
\text { HOUSE6 }\end{array}$ & -28.7 & $29.52 \%$ & 0.29 & 0.37 \\
\hline 20.5 & $20.47 \%$ & $\begin{array}{l}\text { Positive rules } \\
\text { applied to } \\
\text { HOUSE6 }\end{array}$ & 20.7 & $21.69 \%$ & 0.92 & 0.44 \\
\hline-34.2 & $33.56 \%$ & $\begin{array}{l}\text { Negative rules } \\
\text { applied to } \\
\text { HOUSE7 }\end{array}$ & -30.0 & $30.12 \%$ & 0.06 & 0.09 \\
\hline 23.0 & $24.41 \%$ & $\begin{array}{c}\text { Positive rules } \\
\text { applied to } \\
\text { HOUSE7 } \\
\end{array}$ & 20.7 & $21.03 \%$ & 0.21 & $0.15^{\#}$ \\
\hline-26.0 & $25.89 \%$ & $\begin{array}{l}\text { Negative rules } \\
\text { applied to } \\
\text { HOUSE8 }\end{array}$ & -31.2 & $30.82 \%$ & $0.45^{\#}$ & $0.17^{\#}$ \\
\hline 20.0 & $21.16 \%$ & $\begin{array}{l}\text { Positive rules } \\
\text { applied to } \\
\text { HOUSE8 }\end{array}$ & 22.9 & $23.24 \%$ & 0.10 & 0.22 \\
\hline-30.0 & $29.04 \%$ & $\begin{array}{c}\text { Negative rules } \\
\text { applied to } \\
\text { HOUSE9 } \\
\end{array}$ & -28.9 & $28.92 \%$ & 0.65 & 0.96 \\
\hline 22.7 & $23.23 \%$ & $\begin{array}{c}\text { Positive rules } \\
\text { applied to } \\
\text { HOUSE9 } \\
\end{array}$ & 21.4 & $22.24 \%$ & 0.48 & 0.55 \\
\hline-29.7 & $28.44 \%$ & $\begin{array}{l}\text { Negative rules } \\
\text { applied to } \\
\text { HOUSE10 } \\
\end{array}$ & -28.1 & $28.31 \%$ & 0.48 & 0.95 \\
\hline 22.2 & $21.75 \%$ & $\begin{array}{l}\text { Positive rules } \\
\text { applied to } \\
\text { HOUSE10 } \\
\end{array}$ & 20.8 & $22.04 \%$ & 0.46 & 0.87 \\
\hline-30.6 & $30.22 \%$ & $\begin{array}{l}\text { Negative rules } \\
\text { applied to } \\
\text { HOUSE11 }\end{array}$ & -32.1 & $31.93 \%$ & 0.49 & 0.41 \\
\hline 21.8 & $21.85 \%$ & $\begin{array}{c}\text { Positive rules } \\
\text { applied to } \\
\text { HOUSE11 } \\
\end{array}$ & 20.7 & $21.79 \%$ & 0.50 & 0.97 \\
\hline-31.0 & $30.51 \%$ & $\begin{array}{c}\text { Negative rules } \\
\text { applied to } \\
\text { HOUSE12 } \\
\end{array}$ & -27.4 & $28.01 \%$ & 0.12 & 0.23 \\
\hline 20.5 & $21.16 \%$ & $\begin{array}{c}\text { Positive rules } \\
\text { applied to } \\
\text { HOUSE12 }\end{array}$ & 22 & $22.79 \%$ & 0.28 & 0.33 \\
\hline-48.5 & $22.00 \%$ & $\begin{array}{l}\text { Negative rules } \\
\text { applied to LORD } \\
\text { OF 1ST HOUSE }\end{array}$ & -48.7 & $21.71 \%$ & 0.95 & 0.79 \\
\hline 36.2 & $34.32 \%$ & $\begin{array}{c}\text { Positive rules } \\
\text { applied to LORD } \\
\text { OF 1ST HOUSE }\end{array}$ & 37.6 & $35.01 \%$ & 0.52 & 0.64 \\
\hline-49.5 & $22.09 \%$ & $\begin{array}{c}\text { Negative rules } \\
\text { applied to LORD } \\
\text { OF 2ND HOUSE }\end{array}$ & -51.6 & $22.33 \%$ & 0.48 & 0.83 \\
\hline 34.8 & $33.66 \%$ & $\begin{array}{c}\text { Positive rules } \\
\text { applied to LORD } \\
\text { OF 2ND HOUSE }\end{array}$ & 36.5 & $33.70 \%$ & 0.40 & 0.98 \\
\hline-49.4 & $22.09 \%$ & $\begin{array}{c}\text { Negative rules } \\
\text { applied to LORD } \\
\text { OF 3RD HOUSE }\end{array}$ & -49.5 & $22.18 \%$ & 0.98 & 0.94 \\
\hline 38.6 & $33.99 \%$ & $\begin{array}{c}\text { Positive rules } \\
\text { applied to LORD } \\
\text { OF 3RD HOUSE }\end{array}$ & 37.1 & $34.20 \%$ & 0.49 & 0.88 \\
\hline-53.9 & $23.40 \%$ & $\begin{array}{l}\text { Negative rules } \\
\text { applied to LORD } \\
\text { OF 4TH HOUSE }\end{array}$ & -47.3 & $21.24 \%$ & $0.29^{\#}$ & 0.06 \\
\hline 37.1 & $34.84 \%$ & $\begin{array}{l}\text { Positive rules } \\
\text { applied to LORD } \\
\text { OF 4TH HOUSE }\end{array}$ & 36.0 & $33.50 \%$ & 0.63 & 0.38 \\
\hline-50.4 & $22.40 \%$ & $\begin{array}{l}\text { Negative rules } \\
\text { applied to LORD } \\
\text { OF 5TH HOUSE }\end{array}$ & -49.4 & $21.75 \%$ & 0.74 & 0.57 \\
\hline
\end{tabular}




\begin{tabular}{|c|c|c|c|c|c|c|}
\hline 34.7 & $32.09 \%$ & $\begin{array}{c}\text { Positive rules } \\
\text { applied to LORD } \\
\text { OF 5TH HOUSE }\end{array}$ & 36.7 & $33.70 \%$ & 0.37 & 0.26 \\
\hline-52.1 & $21.96 \%$ & $\begin{array}{c}\text { Negative rules } \\
\text { applied to LORD } \\
\text { OF 6TH HOUSE }\end{array}$ & -48.1 & $21.71 \%$ & 0.20 & 0.82 \\
\hline 36.4 & $33.60 \%$ & $\begin{array}{c}\text { Positive rules } \\
\text { applied to LORD } \\
\text { OF 6TH HOUSE }\end{array}$ & 35.9 & $34.24 \%$ & 0.84 & 0.62 \\
\hline-55.3 & $23.88 \%$ & $\begin{array}{c}\text { Negative rules } \\
\text { applied to LORD } \\
\text { OF 7TH HOUSE }\end{array}$ & -49.0 & $21.73 \%$ & $0.31^{\#}$ & 0.05 \\
\hline 3.9 & $32.04 \%$ & $\begin{array}{c}\text { Positive rules } \\
\text { applied to LORD } \\
\text { OF 7TH HOUSE }\end{array}$ & 4.9 & $39.58 \%$ & 0.27 & 0.05 \\
\hline-51.6 & $21.87 \%$ & $\begin{array}{l}\text { Negative rules } \\
\text { applied to LORD } \\
\text { OF 8TH HOUSE }\end{array}$ & -47.9 & $21.15 \%$ & 0.21 & 0.52 \\
\hline 38.2 & $34.45 \%$ & $\begin{array}{c}\text { Positive rules } \\
\text { applied to LORD } \\
\text { OF 8TH HOUSE }\end{array}$ & 38.1 & $35.04 \%$ & 0.98 & 0.68 \\
\hline-51.3 & $22.27 \%$ & $\begin{array}{c}\text { Negative rules } \\
\text { applied to LORD } \\
\text { OF 9TH HOUSE }\end{array}$ & -46.9 & $20.97 \%$ & 0.16 & 0.25 \\
\hline 36.2 & $33.27 \%$ & $\begin{array}{c}\text { Positive rules } \\
\text { applied to LORD } \\
\text { OF 9TH HOUSE }\end{array}$ & 38.4 & $35.37 \%$ & 0.32 & 0.15 \\
\hline-53.7 & $24.37 \%$ & $\begin{array}{l}\text { Negative rules } \\
\text { applied to LORD } \\
\text { OF 10TH HOUSE }\end{array}$ & -49.4 & $22.20 \%$ & 0.16 & 0.06 \\
\hline 35.9 & $33.79 \%$ & $\begin{array}{c}\text { Positive rules } \\
\text { applied to LORD } \\
\text { OF 10TH HOUSE }\end{array}$ & 37.0 & $34.47 \%$ & 0.59 & 0.62 \\
\hline-59.4 & $23.70 \%$ & $\begin{array}{c}\text { Negative rules } \\
\text { applied to LORD } \\
\text { OF 11TH HOUSE }\end{array}$ & -49.3 & $21.69 \%$ & $0.05^{\#}$ & $0.05^{\#}$ \\
\hline 36.9 & $35.17 \%$ & $\begin{array}{c}\text { Positive rules } \\
\text { applied to LORD } \\
\text { OF 11TH HOUSE }\end{array}$ & 36.5 & $35.37 \%$ & 0.82 & 0.88 \\
\hline-52.1 & $22.97 \%$ & $\begin{array}{c}\text { Negative rules } \\
\text { applied to LORD } \\
\text { OF 12TH HOUSE }\end{array}$ & -49.7 & $21.64 \%$ & 0.42 & 0.21 \\
\hline 31.8 & $31.30 \%$ & $\begin{array}{c}\text { Positive rules } \\
\text { applied to LORD } \\
\text { OF 12TH HOUSE }\end{array}$ & 39.0 & $36.31 \%$ & $0.05^{\#}$ & $0.17^{\#}$ \\
\hline \multicolumn{7}{|c|}{$\begin{array}{l}\mathrm{P} \text { values marked with \# are one tailed } \mathrm{p} \text { values calculated for hypothesised difference of } 10 \% \text {, all other values are two tailed } \mathrm{p} \text { values } \\
\text { calculated for hypothesised difference of zero. } \\
\text { Null Hypothesis: Maximum difference between value under test (average compliance score or average number of rules complied) for the } \\
\text { given entity in both groups is less than } 10 \text { percentage. } \\
\text { Conclusion: We cannot reject the Null Hypothesis since p-value of each entity is always }>0.05 \text {. It means for all } 34 \text { entities, the difference } \\
\text { between two groups is not exceeding } 10 \% \text { and the principles involved are invalid. } \\
\text { Neither astrological negativity nor positivity of entities can act as a differentiator. }\end{array}$} \\
\hline
\end{tabular}

Table 8: Compliance of the negative principles tested individually for Rahu

\begin{tabular}{|c|c|c|c|c|c|}
\hline Principle tested & What is tested empirically & $\begin{array}{c}\text { Average } \\
\text { of } \sum \text { CSN } \\
\text { in } \\
\text { Group A }\end{array}$ & $\begin{array}{c}\text { Average of } \\
\sum \text { CSN in } \\
\text { Group B }\end{array}$ & $\begin{array}{c}\text { Two tailed P } \\
\text { value for } \sum \text { CSN } \\
\text { (Hypothesised } \\
\text { difference = 0) }\end{array}$ & Conclusions \\
\hline $\begin{array}{c}\text { Principle 1.1: Planet } \\
\text { in conjugation or } \\
\text { square or opposite to } \\
\text { Saturn, Mars, or } \\
\text { Uranus }\end{array}$ & $\begin{array}{c}\text { Probability of Rahu having a } \\
\text { difference* of 0, 90, or 180 } \\
\text { degrees with one of the three } \\
\text { planets namely Saturn, Mars } \\
\text { or Uranus. }\end{array}$ & -12.46 & -12.61 & 0.93 & $\begin{array}{c}\text { No significantly higher } \\
\text { percentage of such } \\
\text { configurations in Group A as } \\
\text { against Group B hence rule is } \\
\text { invalid }\end{array}$ \\
\hline $\begin{array}{c}\text { Principle 1.2: Planet } \\
\text { in debilitated state in } \\
\text { D9 chart }\end{array}$ & $\begin{array}{c}\text { For D9 charts, probability of } \\
\text { Rahu in a zodiac sign that is } \\
\text { considered as debilitated or } \\
\text { enemy sign }\end{array}$ & -1.89 & -1.85 & 0.93 & Rule invalid \\
\hline $\begin{array}{c}\text { Principle 1.3: Planet } \\
\text { in 6 }{ }^{\text {th }}, 8 \text { th } \text { or 12 th } \\
\text { house }\end{array}$ & $\begin{array}{c}\text { Probability that a planet is in } \\
\text { the zodiac sign of } x+5, \mathrm{x}+7,\end{array}$ & -5.20 & -4.58 & 0.35 & $\begin{array}{c}\text { Planet does not have a } \\
\text { significantly higher } \\
\text { probability to get placed in }\end{array}$ \\
\hline
\end{tabular}




\begin{tabular}{|c|c|c|c|c|c|}
\hline & $\begin{array}{l}\text { or } x+11 \text { when } x \text { is the zodiac } \\
\text { sign number of Ascendant. }\end{array}$ & & & & $\begin{array}{l}\text { these houses when the } \\
\text { natives are having cancer }\end{array}$ \\
\hline $\begin{array}{l}\text { Principle 1.4: Planet } \\
\text { in malefic nakshatra } \\
\text { namely Krittika, } \\
\text { Ashelsha, Mul }\end{array}$ & $\begin{array}{l}\text { Probability of degrees of the } \\
\text { planet Rahu being in a range } \\
\text { that correlates to Krittika, } \\
\text { Ashelsha or Mul nakshatras }\end{array}$ & -1.50 & -1.81 & 0.46 & $\begin{array}{l}\text { No significant difference in } \\
\text { both groups }\end{array}$ \\
\hline $\begin{array}{l}\text { Principle 1.6: Planet } \\
\text { afflicted by } 3^{\text {rd }} \text { or } 10^{\text {th }} \\
\text { aspect of Saturn or } 4^{\text {th }} \\
\text { or } 8^{\text {th }} \text { aspect of Mars }\end{array}$ & $\begin{array}{l}\text { Probability that differences of } \\
\text { degrees* of Rahu and Saturn } \\
\text { are } 60 \text { or } 270 \text { OR the } \\
\text { difference between Rahu and } \\
\text { Mars is } 90 \text { or } 210 \text { degrees }\end{array}$ & -2.38 & -2.35 & 0.95 & $\begin{array}{c}\text { Rahu is impacted equally by } \\
\text { 3rd or 10th aspect of Saturn } \\
\text { or 4th / 8th aspect of Mars in } \\
\text { both the groups }\end{array}$ \\
\hline $\begin{array}{l}\text { Principle 1.7: Lord of } \\
\text { planet's house is in } \\
\text { debilitated or in } \\
\text { enemy sign }\end{array}$ & $\begin{array}{l}\text { Probability that planet which } \\
\text { acts as lord of house in which } \\
\text { Rahu is placed is in } \\
\text { debilitated or in enemy sign }\end{array}$ & -8.03 & -6.59 & 0.10 & Rule invalid \\
\hline $\begin{array}{c}\text { Principle 1.8: Planet } \\
\text { itself in debilitated or } \\
\text { enemy sign }\end{array}$ & $\begin{array}{l}\text { Probability of Rahu to be in a } \\
\text { zodiac sign that is considered } \\
\text { as debilitated or enemy signs }\end{array}$ & -4.77 & -4.39 & 0.55 & $\begin{array}{c}\text { No relation of Rahu being in } \\
\text { debilitation or enemy sign } \\
\text { with prediction }\end{array}$ \\
\hline $\begin{array}{l}\text { Principle 1.9: Planet is } \\
\text { in conjugation with } \\
\text { lord of } 6^{\text {th }} \text { or } 8^{\text {th }} \text { or } \\
12^{\text {th }} \text { house. }\end{array}$ & $\begin{array}{l}\text { Probability that the Rahu is in } \\
\pm 4 \text { degrees of the degrees of } \\
\text { planets which act as lord of } \\
\text { 6th, 8th or 12th house }\end{array}$ & -2.91 & -3.86 & 0.14 & $\begin{array}{l}\text { Rule invalid, no relation to } \\
\text { prediction }\end{array}$ \\
\hline \multicolumn{6}{|c|}{$\begin{array}{l}\text { *allowing tolerance of } \pm 4 \text { degrees as per standard practice } \\
\text { Note: Principle } 1.5 \text { of Table } 1 \text { is not applicable to Rahu. } \\
\text { Null Hypothesis: Average compliance score of negative rules in both groups are equal } \\
\text { Conclusion: We cannot reject the Null Hypothesis since p-value is always }>0.05 \text {. The rules tested do not prove empirically for Rahu and } \\
\text { therefore are invalid. }\end{array}$} \\
\hline
\end{tabular}

\section{Conclusions}

In the absence of a unanimous and an authentic list of astrological principles available for testing, the comprehensive test consisting of the comparison of astrological positivity and negativity of all entities (planets, houses and lords of houses) was demonstrated as a potential empirical approach to statistically test some of the most fundamental principles of astrology. If those principles were true, we should have seen significant differences in the two groups for at least one parameter in the test, but there were none. This disproved their validity. While there could be arguments on what additional rules we should have tested, the results we presented deserves explanation on the basis of astrology as to why none of the 34 entities could show any difference in terms of astrological negativity or positivity between two groups despite completely opposite life patterns. Each of these principles was further tested individually for Rahu, Mars and Sun but the number of cases complying with the rule were not significantly different in two groups which further conformed invalidity of the principle involved. As these principles are intrinsic and an essential part of astrology, they are invariably used in everyday practice. This certainly poses many questions about the prediction accuracy of astrology in general and deserves more tests and investigations.

\section{Acknowledgement}

We are grateful to Astro-databank (Lois Rodden's Astro Databank) from which we extracted the data used in this experiment. The collection of such data worldwide with so much detail is a huge effort and is a vital input to our research work.

\section{References}

1. Agarwal GS. Practical Vedic astrology, Sagar Publication, New Delhi, India, 2019.

2. Anagha Anigol, Prasanna Mathad, Rajashree Chitree. A review on medical astrology with respect to arishta lakshana, International Journal of Multidisciplinary Educational Research. 2020;5(8):18-24.

3. Balaji Deekshitulu PV. Astrology and mental health, International Journal of Philosophical Research. 2019;1:1.

4. Bhandary R, Sharma PS, Tharoor H. Prediction of mental illness using Indian astrology: Cross-sectional findings from a prospective study. Journal of Scientific Exploration.

2018;32(3):555-578. doi: $10.31275 / 2018 / 1260$

5. Carlson S. A double-blind test of astrology. Nature. 1985;318:419-425.

6. Chatterjee SS. Advanced medical astrology. Rave Publication, New Delhi, India, 2017.

7. Dean G, Mather A. Sun sign columns, Skeptical Enquirer. 2000;24(5):36-40.

8. Dean G, Kelly IW. Is astrology relevant to consciousness and psi? Journal of Consciousness Studies. 2003;10(67):175-198. Retrieved from http://www.imprint.co.uk/pdf/Dean.pdf

9. Dean G, Mather A, Nias D, Smit R. Tests of astrology. Amsterdam: AinO Publications, 2016.

10. Ertel S. Appraisal of Shawn Carlson's renowned astrology tests. Journal of Scientific Exploration. 2009;23(2):125-137.

11. Eysenck HJ. Critique of "A double-blind test of astrology". Astro-Psychological Problems. 1986;4(1):78.

12. Hamilton TW. Critique of the Carlson study. AstroPsychological Problems. 1986;4(1):9-12.

13. Krishna Murthy Kavirayani. Astrology and mental illness, AP J Psychol Med. 2013;14(2):95-102.

14. Krishna Prasad Subedi, Binay Thakur, Sadina Shrestha, Soma Kanta Baral, Prativa Neupane, Suk Bahadur Tamang et al. Medical \& astrological study on the impact of celestial bodies for cancer-susceptibility-A case study, JETIR. 2019;6:194-200.

15. Lois Rodden's Astro Databank 2008. https://www.astro.com/astro-databank/Main_Page 
16. Lois Rodden's Astro Databank 2008. https://en.wikipedia.org/wiki/Astrodatabank

17. Narlikar JV, Kunte S, Dabholkar N, Ghatpande P. A statistical test of astrology. Current Science. 2009;96:641-643.

18. Narlikar Jayant V. An Indian test of Indian astrology, Skeptical Enquirer. 2013;3:45-49.

19. Oshop R, Foss A. Twitter followers biased to astrological charts of celebrities. Journal of Scientific Exploration. 2005;29(1):11-36.

20. Public Service of Creative Research Systems https://surveysystem.com/sscalc.htm

21. Raman BV. Hindu predictive astrology, Raman Publications, Bangalore, 1963.

22. Raman BV. Astrology for beginners, UBS Publishers Distributors Ltd, New Delhi, India, 1996.

23. Rao Narasimha PVR. Vedic astrology: An integrated approach, Sagar Publications, New Delhi, India, 2004. https://www.vedicastrologer.org/articles/astro_books.ht $\mathrm{m}$

24. Rao Narasimha PVR. Building blocks of Vedic astrology, 2004.

https://www.vedicastrologer.org/articles/astro_articles.h tm

25. Rath Sanjay. Crux of Vedic astrology, Sagar Publications, New Delhi, 2012.

26. Rath Sanjay. Introduction to Vedic astrology, Sagittarius Publications, New Delhi, India, 2018. http://www.panchanga.lv/wpcontent/uploads/2020/06/Introduction-to-VedicAstrology-Sanjay-Rath.pdf

27. Sharma, Bhuvnesh, Prasad P, Narayana A. Contribution of astrology in medicine - a review. Bulletin of the Indian Institute of History of Medicine (Hyderabad). 2007;37:45-62.

28. Trivedi Mridula TP. Astrology for overcoming cancer, Alpha publications, India, 2017, 245-313. 